\title{
Preliminary report from an randomized clinical trial on intra-procedural three-dimensional rotational angiography in cryoballoon ablation for atrial fibrillation
}

\author{
DIvan Prepolec *, \\ (D) Vedran Pašara, \\ (DBorka Pezo-Nikolić, \\ (D)Mislav Puljević, \\ DDavor Puljević, \\ DDavor Miličić, \\ (1)Vedran Velagić
}

University of Zagreb School of Medicine, University Hospital Centre Zagreb, Zagreb, Croatia

RECEIVED:

December 14, 2020

ACCEPTED:

December 18, 2020

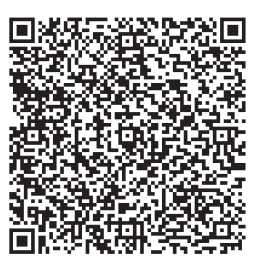

$\square$ Cardiologia Croatica 2021;16(1-2):14.

\begin{abstract}
KEYWORDS: atrial fibrillation, cryoballoon ablation, three-dimensional rotational angiography. CITATION: Cardiol Croat. 2021;16(1-2):14. | https://doi.org/10.15836/ccar2021.14

*ADDRESS FOR CORRESPONDENCE: Ivan Prepolec, Klinički bolnički centar Zagreb, Kišpatićeva 12, HR-10000 Zagreb, Croatia. / Phone: +395-95-8405437 / E-mail: iprepolec@gmail.com

ORCID: Ivan Prepolec, https://orcid.org/0000-0001-5870-202X • Vedran Pašara, https://orcid.org/0000-0002-6587-2315 Borka Pezo-Nikolić, https://orcid.org/0000-0002-0504-5238 • Mislav Puljević, https://orcid.org/0000-0003-1477-2581 Davor Puljević, https://orcid.org/0000-0003-3603-2242 • Davor Miličić, https://orcid.org/0000-0001-9101-1570 Velagić Vedran, https://orcid.org/0000-0001-5425-5840
\end{abstract}

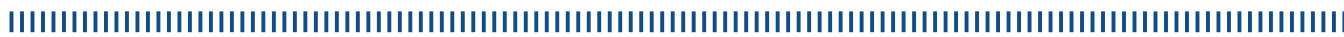

Introduction: There is a variety of approaches to pre-procedural imaging of pulmonary veins (PV) and left atrium (LA) in order to facilitate atrial fibrillation (AF) ablation, including CT angiography, cardiac MRI and intra-procedural three-dimensional rotational angiography (3DRA). Data supporting different practices is still evolving and there is an open question whether LA imaging could improve safety and outcomes of cryoballoon ablation (CB) ablation., ${ }^{1,2}$ Here we present the preliminary data from a singlecentre unblinded randomized clinical trial

Patients and Methods: So far, we recruited 82 patients (68.3\% male, 59.0 \pm 11.6 years) with paroxysmal (92.8\%) and early-persistent AF. Patients were randomized to no imaging or 3DRA which was performed intra-procedurally after trans-septal puncture. Angiographic images were segmented and overlaid to the fluoroscopy screen to guide the ablation procedure. All patients are followed for 1 year and data concerning procedural characteristics, safety outcomes and AF recurrence are being collected.

Results: Of 82 patients recruited so far, 40 (48\%) underwent 3DRA. In patients who received no imaging (non-3DRA group) all PVs were successfully isolated while in 3DRA group isolation of one PV could not be achieved in 1 patient. Procedure time was significantly longer when 3DRA was performed $(89.4 \pm 29.7$ min compared to $69.4 \pm 21.4$ in non-3DRA group, $\mathrm{p}<0.001)$. Total radiation dose $(146.9 \pm 186.1$ vs $399.8 \pm 216.5$ $\mathrm{mGy}, \mathrm{p}<0.001)$ and contrast administration $(44.2 \pm 27.6 \mathrm{vs} 136.8 \pm 28.4 \mathrm{ml})$ were significantly lower in the control group. Only minor complications were reported in both groups. Three patients developed large hematoma (2 in 3DRA group vs 1 in control group). In each group there was one incident of transient phrenic nerve palsy

Conclusion: 3DRA is a safe and efficient intra-procedural imaging method to guide CB ablation for AF. However, it significantly increases procedure duration, total radiation dose and contrast expenditure. In our trial it did not have any impact on the acute success rate of PV isolation. One-year follow up data is still being collected and will subsequently be presented.

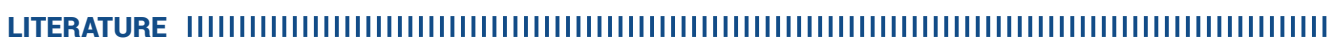

1. Donal E, Lip GY, Galderisi M, Goette A, Shah D, Marwan M, et al. EACVI/EHRA Expert Consensus Document on the role of multi-modality imaging for the evaluation of patients with atrial fibrillation. Eur Heart J Cardiovasc Imaging. 2016 Apr;17(4):355-83. https://doi.org/10.1093/ehjci/jev354

2. Sagone A, lacopino S, Pieragnoli P, Arena G, Verlato R, Molon G, et al Cryoballoon ablation of atrial fibrillation is effectively feasible without previous imaging of pulmonary vein anatomy: insights from the 1STOP project. J Interv Card Electrophysiol. 2019 Sep:55(3):267-275. https://doi.org/10.1007/s10840-018-0500-6 